\title{
Are probiotics effective in reversing non-alcoholic steatohepatitis?
}

\author{
Ludovico Abenavoli $^{1}$, Luigi Boccuto ${ }^{2}$, Emidio Scarpellini $^{3}$ \\ ${ }^{1}$ Department of Health Sciences, University Magna Graecia, Catanzaro, Italy; ${ }^{2}$ School of Nursing, Clemson University, Clemson, SC, USA; \\ ${ }^{3}$ Translational Research Center for Gastrointestinal Disorders, Department of Chronic Diseases, Metabolism and Ageing, Catholic University of \\ Leuven, Leuven, Belgium \\ Correspondence to: Ludovico Abenavoli, MD, PhD. Department of Health Sciences, University "Magna Graecia”, Viale Europa, 88100 Catanzaro, \\ Italy. Email: 1.abenavoli@unicz.it. \\ Comment on: Jena PK, Sheng L, Li Y, et al. Probiotics VSL\#3 are effective in reversing non-alcoholic steatohepatitis in a mouse model. Hepatobiliary \\ Surg Nutr 2020;9:170-82.
}

Submitted Feb 24, 2021. Accepted for publication Mar 11, 2021.

doi: 10.21037/hbsn-21-85

View this article at: http://dx.doi.org/10.21037/hbsn-21-85

The gut microbiota (GM) is an integrated ecosystem of tens of trillions of microorganisms, as actinomyces, archaea, protozoa, and last but not least viruses, including one thousand different species of known bacteria with an overall count of more than three million genes, 150 times more than the human genome. GM presents immunemodulating, absorptive and metabolic functions (1). Antibiotics first and more recently probiotics-alive microorganisms beneficially affecting human healthrepresent the most significant agents capable of modulating GM composition (1). In current clinical practice, single and multi-strain preparations of probiotics, are used in gastrointestinal and non-gastrointestinal diseases with curative significant and promising results. In particular, the multistrain VSL $\# 3{ }^{\circledR}$ is often used for the treatment and maintenance period of ulcerative colitis (2).

The gut-liver axis consists of the interaction between GM, liver metabolism, and immune system; disruptions of this axis have been proved to be among the pathophysiological mechanisms associated with the onset and development of non-alcoholic fatty liver disease (NAFLD), non-alcoholic steatohepatitis (NASH), until liver cirrhosis and cancer development (HCC) (3). Functional studies have shown how altered GM can dysregulate the opening of inter-enterocytes tight-junctions (TJ), responsible for the maintenance of the adequate gut permeability to antigens, toxic substances from intestinal lumen until bloodstream and liver are reached (3). Antibiotics and probiotics can regulate the gut-liver axis and have beneficial effects on NAFLD, NASH, liver cirrhosis, and HCC presentation and prevention (3). To date, there is only scarce evidence on the efficacy of certain probiotics on liver fat deposition, down-regulation of the inflammatory cascade, improvement of metabolic parameters in animal models (Table 1), and remission of symptoms in patients with ulcerative colitis (2).

Several animal models have shown that VSL\#3 protects against NASH both in chemically-induced (dextran sulfate sodium-treated ApoE-/- mice) and diet-related (high fat diet-fed young rats and genetic ob/ob mice) setups (4). Moreover, in a particular diet-related NASH model, namely methionine-choline-deficient (MCD) diet-induced, VSL\#3 failed to prevent both liver steatosis and inflammation although improved hepatic fibrosis (5). This finding is of great interest if compared to the possible impact on humans' health. In fact, the ketogenic high-fat diet is often used for brief periods to lose weight in particular categories as obese and bodybuilders and resulting in improved insulin sensitivity (1).

In light of these proven effects of VSL\#3, the study of Jena $e t a l$. is of particular importance for the investigation of the potential effects of this multistrain probiotic preparation on several pathways of NASH development and carcinogenesis. The study employed a specific human-like animal model, farnesoid X receptor (FXR) knockout (KO) mice, which presented elevated BAs and developed steatosis and NASH, progressing spontaneously to liver cancer (4). These findings are consistent with previous works showing that inhibition of intestinal FXR signaling reduces obesity, insulin resistance, and fatty liver disease by modulation 
Table 1 Main studies on animal models of NAFLD/NASH via gut microbiota modulation

\begin{tabular}{|c|c|c|}
\hline Author & Animal model & Effects on liver via gut microbiota modulation \\
\hline Pierantonelli et al., 2017 & NIrp3 knockout mice & $\begin{array}{l}\text { Abundance of Gram-negative species and translocation } \\
\text { of bacteria were reduced after antibiotics, repairing liver } \\
\text { and adipose tissue damages }\end{array}$ \\
\hline Llorente et al., 2017 & $\begin{array}{l}\text { Sublytic Atp4aSI/SI mice treated with proton } \\
\text { pump inhibitors }\end{array}$ & $\begin{array}{l}\text { Gut microbiota derangement and progression of liver } \\
\text { disease }\end{array}$ \\
\hline Sheng et al., 2017 & WD-fed FXR KO male mice & Most serious NASH, greatest potential to develop HCC \\
\hline Gart et al., 2018 & Leiden mice & $\begin{array}{l}\text { Gut microbiota changes and plasmatic/intestinal fatty } \\
\text { acids concentration }\end{array}$ \\
\hline Chen et al., 2019 & SIRT3 knockout HFD fed mice & $\begin{array}{l}\text { Impairment of dysbiosis after HFD, } \uparrow \text { LPS levels and dys- } \\
\text { function, } \uparrow \text { cannabinoid receptor } 1 \text { and } 2 \text { expressions in } \\
\text { the colon and liver }\end{array}$ \\
\hline Sun et al., 2019 & Hamsters & $\begin{array}{l}\text { Microbial modulation of bile acids metabolism, improve- } \\
\text { ment of obesity-induced metabolic disorders }\end{array}$ \\
\hline Schneider et al., 2019 & $\begin{array}{l}\text { Methionine-choline deficient diet in rats with } \\
\text { induced NASH }\end{array}$ & $\begin{array}{l}\downarrow \text { Gut microbiota diversity (different from human NASH } \\
\text { patients) }\end{array}$ \\
\hline Petrov et al., 2019 & $\begin{array}{l}\text { Germ-free, high-fat diet non-responder, } \\
\text { Quercetin-supplemented HFD fed mice }\end{array}$ & $\begin{array}{l}\uparrow \text { Stimulation of hepatic bile acid transporters, } \downarrow \text { hepatic } \\
\text { lipogenic and bile acid synthesis genes }\end{array}$ \\
\hline Ahmad et al., 2020 & C57BL/6J HFD fed mice & HFD induced gut microbiota changes \\
\hline Cavallari et al., 2020 & NOD2 knockout mice & $\begin{array}{l}\text { Gut microbiota changes, NAFLD development } \\
\text { NOD2-dependent protection }\end{array}$ \\
\hline
\end{tabular}

HFD, high-fat diet; LPS, lipopolysaccharide; NAFLD, non-alcoholic fatty liver disease; NASH, non-alcoholic steatohepatitis; NIrp3, NLR family pyrin domain containing 3; NOD2, nucleotide-binding oligomerization domain-containing protein 2; SIRT3, NAD-dependent deacetylase sirtuin-3.

of hepatic and gut bacteria-mediated BA metabolism, and intestinal ceramide synthesis (6), while reduced expression of FXR has been detected in patients with liver cirrhosis and HCC (3). As BAs are produced by the conversion of hepatic cholesterol through hepatic and gut microbial enzymes, both nutrients and/or GM can affect metabolism and inflammation.

Sheng et al. chose this experimental animal model also according to previous data from their group showing that WD-fed FXR KO male mice have the most serious NASH and the greatest potential to develop HCC, as compared to WD-fed wildtype (WT) mice or healthy diet-fed FXR KO mice, irrespective of sex (7). VSL\#3 was very effective in preventing hepatic lymphocyte infiltration and reduced hepatic cholesterol and triglycerides content. More interestingly, VSL\#3 administration normalized expression of BA homeostasis genes, increased G-protein coupled BA receptor 1 (GPBAR1)-regulated signaling. These antiinflammatory and anti-carcinogenic effects were consensual to GM reshuffling.

This study adds new pieces of evidence to the puzzle of microbial maps linked to NASH development/regression. Moreover, this investigation is in favor of using probiotics in the field of cancer prevention, a strategy acquiring growing evidence according to several positive findings in HCC from different causes as hepatitis B and C chronic infection, alcohol-related liver cirrhosis, and autoimmune liver diseases (8).

However, this study presents some limitations. It did not investigate the effect of a multistrain probiotic in 
simple liver steatosis. Furthermore, little is known on the impact of single-strain probiotic belonging to VSL\#3 on NASH development and single hepatic pathophysiological pathways. Neither strain-specific anti-carcinogenic effects have been investigated. Four months of VSL\#3 supplementation are effective in NASH prevention in this mice model. However, these findings must be verified in human NASH patients. In this case, several issues have to be addressed, such as what single-strain or multistrain is likely to be more or at least as effective as in animal models or what dosage and for how long to treat patients, what is the impact of different dietetic regimens and lifestyles on the outcome of the treatment with VSL\#3. In fact, the length of the protocol adopted in this paper raises the question about considering probiotics as an add-on treatment or as a long-term main-stay in lower inflammation and anti-cancerogenic state maintenance such as in IBD.

All these issues may seem drawbacks in the use of probiotics for NASH and HCC prevention in humans, while this and other incoming studies are unraveling the strain-specific, dose-finding, and duration of probiotics use in NAFLD to NASH and liver cirrhosis progression in humans. This could have long-term implications in HCC and liver cirrhosis prevention although dramatic diabetes and obesity epidemics are coming in this increasingly Westernized world.

\section{Acknowledgments}

Funding: None.

\section{Footnote}

Provenance and Peer Review: This article was commissioned by the editorial office, Hepatobiliary Surgery and Nutrition. The article did not undergo external peer review.

Conflicts of Interest: All authors have completed the ICMJE uniform disclosure form (available at https://hbsn. amegroups.com/article/view/10.21037/hbsn-21-85/coif). The authors have no conflicts of interest to declare.

Ethical Statement: The authors are accountable for all aspects of the work in ensuring that questions related to the accuracy or integrity of any part of the work are appropriately investigated and resolved.
Open Access Statement: This is an Open Access article distributed in accordance with the Creative Commons Attribution-NonCommercial-NoDerivs 4.0 International License (CC BY-NC-ND 4.0), which permits the noncommercial replication and distribution of the article with the strict proviso that no changes or edits are made and the original work is properly cited (including links to both the formal publication through the relevant DOI and the license). See: https://creativecommons.org/licenses/by-nc-nd/4.0/.

\section{References}

1. Abenavoli L, Scarpellini E, Colica C, et al. Gut Microbiota and Obesity: A Role for Probiotics. Nutrients 2019;11:2690.

2. Bibiloni R, Fedorak RN, Tannock GW, et al. VSL\#3 probiotic-mixture induces remission in patients with active ulcerative colitis. Am J Gastroenterol 2005;100:1539-46.

3. Scarpellini E, Fagoonee S, Rinninella E, et al. Gut Microbiota and Liver Interaction through Immune System Cross-Talk: A Comprehensive Review at the Time of the SARS-CoV-2 Pandemic. J Clin Med 2020;9:2488.

4. Jena PK, Sheng L, Li Y, Wan YY. Probiotics VSL\#3 are effective in reversing non-alcoholic steatohepatitis in a mouse model. Hepatobiliary Surg Nutr 2020;9:170-82.

5. Velayudham A, Dolganiuc A, Ellis M, et al. VSL\#3 probiotic treatment attenuates fibrosis without changes in steatohepatitis in a diet-induced nonalcoholic steatohepatitis model in mice. Hepatology 2009;49:989-97.

6. Sun L, Cai J, Gonzalez FJ. The role of farnesoid X receptor in metabolic diseases, and gastrointestinal and liver cancer. Nat Rev Gastroenterol Hepatol 2021;18:335-47.

7. Sheng L, Jena PK, Liu HX, et al. Gender Differences in Bile Acids and Microbiota in Relationship with Gender Dissimilarity in Steatosis Induced by Diet and FXR Inactivation. Sci Rep 2017; 7:1748.

8. Preveden T, Scarpellini E, Milić N, et al. Gut microbiota changes and chronic hepatitis $\mathrm{C}$ virus infection. Expert Rev Gastroenterol Hepatol 2017;11:813-19.

Cite this article as: Abenavoli L, Boccuto L, Scarpellini E. Are probiotics effective in reversing non-alcoholic steatohepatitis? HepatoBiliary Surg Nutr 2021;10(3):407-409. doi: 10.21037/ hbsn-21-85 